CHRONIC OBSTRUCTIVE PULMONARY DISEASE

\title{
Lung function decline and outcomes in an elderly population
}

D M Mannino, K J Davis

See end of article for authors' affiliations .....................

Correspondence to: Dr D M Mannino, Division of Pulmonary and Critical Care Medicine, University of Kentucky Medical Center, 740 S Limestone, $\mathrm{K}-528$, Lexington, $\mathrm{KY}$ 40536, USA; dmannino@ uky.edu

Received 1 September 2005 Accepted

16 February 2006

Published Online First

3 March 2006
Objective: To determine the risk factors for and outcomes associated with the rapid decline in lung function in a cohort of elderly US adults.

Methods: Data from 4923 adult participants aged 65 years and older at baseline in the Cardiovascular Health Study were analysed. Subjects were classified using a modification of the GOLD criteria for chronic obstructive pulmonary disease (COPD) and a "restricted" category (FEV 1 /FVC $\geqslant 70 \%$ and FVC $<80 \%$ predicted) was added. Cox proportional hazard models were used to determine the risk of lung function decline over 4 years on subsequent mortality and COPD hospital admissions after adjusting for age, race, sex, smoking status, and other factors.

Results: Of the participants in the initial cohort, $3388(68.8 \%)$ had spirometric tests at the year 4 visit. Participants with GOLD stages 3 or 4 COPD at baseline were less likely than normal subjects to have follow up spirometric tests $(52.7 \% \vee 77.9 \%, \mathrm{p}<0.01)$ and were more likely to be in the most rapidly declining quartile of $\mathrm{FEV}_{1}(28.2 \% \vee 21.3 \%, \mathrm{p}<0.01)$ with an annual loss of $\mathrm{FEV}$, of at least $3.5 \%$. Overall, being in the most rapidly declining quartile of FEV from baseline to year 4 was associated with an increased risk of admission to hospital for COPD (adjusted hazard ratio (HR) 1.6, 95\% confidence interval (Cl) 1.3 to 2.0 ) and all-cause death (adjusted HR 1.5, 95\% $\mathrm{Cl} 1.2$ to 1.7) over an additional 7 years of follow up.

Conclusion: More rapid decline in lung function is independently associated with a modest increased risk of hospital admissions and deaths from COPD in an elderly cohort of US participants. c hronic obstructive pulmonary disease (COPD) is an important cause of morbidity and mortality in the United States and around the world. ${ }^{12}$ The definition of COPD has evolved over time from one based on a clinical diagnosis of chronic bronchitis or anatomical findings of emphysema to one based on the presence of abnormal lung function. ${ }^{3}{ }^{4}$ Lung function is a strong predictor of survival, ${ }^{5}$ lung cancer development, ${ }^{6}$ and functional limitations. ${ }^{7}$ Recent work, however, has emphasised the importance of measures other than pulmonary function in the prognosis of patients with COPD. ${ }^{8}$

Impaired lung function has previously been shown to predict mortality, ${ }^{10-14}$ although none of these studies classified lung function according to the recently developed international Global Initiative on Obstructive Lung Disease (GOLD) guidelines for the staging of COPD severity. ${ }^{3}$ The decline in the forced expiratory volume in 1 second $\left(\mathrm{FEV}_{1}\right)$ is also an important predictor of morbidity and mortality, although most subjects in these studies had COPD or lung function impairment at baseline. ${ }^{15-17}$ The GOLD guidelines do not categorise subjects with "restrictive disease" - that is, subjects with a low forced vital capacity (FVC) but normal $\mathrm{FEV}_{\mathrm{l}} / \mathrm{FVC}$. Previous work has suggested that subjects with this abnormality also have an increased risk of death. ${ }^{5}{ }^{18}$

We used a modification of the GOLD classification criteria, incorporating a classification for restrictive disease, to examine the association between impaired lung function at baseline and lung function decline over 4 years and outcomes, including COPD related admission to hospital and allcause mortality, in a large cohort of US adults aged 65 and older at baseline and followed for up to 7 years after the second pulmonary function evaluation.

\section{METHODS}

\section{Study background}

The original Cardiovascular Health Study (CHS) cohort of 5201 men and women was selected using Medicare eligibility lists provided by the US Health Care Financing Administration for four communities: Forsyth County, North Carolina; Pittsburgh, Pennsylvania; Sacramento County, California; and Washington County, Maryland during the period from May 1989 to May $1990 .{ }^{19}$ Spirometric testing was conducted at baseline and at 4 years. In addition to the questionnaire and spirometric data, our analytical dataset included hospitalisation data, which allowed us to classify "COPD-related hospitalisations" through 1999. CHS participants underwent pulmonary function testing during a baseline clinical examination and provided information on history of respiratory symptoms and diagnoses, body mass index (BMI), smoking history, and medical history. Study protocols were approved for protection of human subjects. Details of the CHS are published elsewhere. ${ }^{19}$

\section{Study population}

Our analysis was limited to CHS participants who provided baseline information on respiratory symptoms and diagnoses, underwent pulmonary function testing at the baseline examination, and for whom follow up data were available. Analyses incorporating lung function decline as either an outcome or predictive variable were limited to subjects who had pulmonary function testing done at the baseline visit and visit 6 (approximately 4 years after the baseline visit).

\section{Pulmonary function data}

Spirometric tests were conducted using a volume displacement water sealed spirometer. At least three acceptable spirograms were obtained from a minimum of five forced expirations. The best single spirogram was identified by

Abbreviations: $\mathrm{BMI}$, body mass index; $\mathrm{COPD}$, chronic obstructive pulmonary disease; $F E V_{1}$, forced expiratory volume in 1 second; $F V C$, forced vital capacity 
computer and confirmed by a technician. Quality assurance was provided by the CHS Pulmonary Function Center and the procedures followed contemporary American Thoracic Society guidelines. ${ }^{20}$ Several measures of lung function were used: forced expiratory volume in 1 second $\left(\mathrm{FEV}_{1}\right)$, forced vital capacity (FVC), and $\mathrm{FEV}_{\mathrm{l}} / \mathrm{FVC}$ ratio. The Knudson prediction equations were used to determine the "normal" values of $\mathrm{FEV}_{1}$ and FVC based on age, sex, and race. ${ }^{21}$

\section{Variable definition}

Age, sex, race, and highest education level obtained were self-reported. Age was stratified into 4 year categories, race was classified as white or black, and education level was classified as $<12$ years, 12 years, or $>12$ years.

Respondents with positive responses to "Have you ever smoked cigarettes?" and "Do you now smoke cigarettes?" were classified as "ever smokers" and "current smokers," respectively. Pack-years of cigarettes smoked were calculated for current and former smokers. BMI was calculated as weight divided by height squared $\left(\mathrm{kg} / \mathrm{m}^{2}\right){ }^{22}$

We defined a participant as having a respiratory symptom (used to classify GOLD 0 lung function status) if they responded positively to any of the following questions: "Do you usually have a cough?"; "Do you usually bring up phlegm from your chest?"; "Does your chest ever sound wheezy or whistling apart from colds?"; "Do you have to walk slower than people of your age on the level because of breathlessness?"; "Are you too breathless to leave the house or breathless on dressing or undressing?"

Using a modification of the criteria developed by GOLD, ${ }^{3}$ we classified subjects according to their GOLD stages of COPD: GOLD stage 3 or $4\left(\mathrm{FEV}_{1} / \mathrm{FVC}<0.70\right.$ and $\mathrm{FEV}_{1}<50 \%$ predicted $)$, GOLD stage $2\left(\mathrm{FEV}_{1} / \mathrm{FVC}<0.70\right.$ and $\mathrm{FEV}_{1} \geqslant 50$ to $<80 \%$ predicted), GOLD stage $1\left(\mathrm{FEV}_{1} / \mathrm{FVC}<0.70\right.$ and $\mathrm{FEV}_{1}$ $\geqslant 80 \%)$, restricted $\left(\mathrm{FEV}_{\mathrm{l}} / \mathrm{FVC} \geqslant 0.70\right.$ and $\mathrm{FVC}<80 \%$ predicted), GOLD stage 0 (presence of respiratory symptoms in the absence of any lung function abnormality), and no lung disease. Bronchodilator response was not evaluated in this survey so classification is based on the "prebronchodilator" level.

Subjects with a rapid decline in lung function were identified on the basis of lung function values at the baseline evaluation and at the follow up examination at approximately 4 years. We determined the quartiles of the change (determined as an annual percentage change from the baseline level) in the $\mathrm{FEV}_{1}$ and classified those in the most negative category as "rapid decliners" and the other three categories as the referent group. For $\mathrm{FEV}_{1}$, the rapid decliners lost a median of $4.7 \%$ (range $3.5-22.7 \%$ ) of their baseline value per year.

Subjects were classified as having diabetes if they either reported a diagnosis of diabetes at baseline or had impaired fasting or post glucose load glucose $(>140)$ at the examination. Subjects reporting a diagnosis of a previous myocardial infarction, stroke, heart failure, angina, or transient ischaemic attacks were classified as having cardiovascular disease at the baseline examination. BMI was determined by dividing the measured weight in kilograms by the height in meters squared and was stratified into four categories: $\leqslant 20,21-24$, $25-29$ and $\geqslant 30 \mathrm{~kg} / \mathrm{m}^{2}$.

Exercise category was determined using a combination of self-reported exertion (based on reported activities at work, home and leisure) and the number of blocks walked in the previous week. Both of these measures were divided into quartiles and the level was classified based on the highest of either of these categories.

Subjects completed the Centers for Epidemiologic Studies Depression (CESD) scale to self-report the presence and persistence of depressive symptoms. ${ }^{23}$ This version of the
CESD consisted of 10 items which are scored from 0 to 3 points, depending on their frequency during the past week. We divided the scores from this scale into quartiles and considered subjects in the highest quartile (scores of 7 or higher) as "depressed". ${ }^{23}$

\section{Deaths}

Death information coded in the CHS database was obtained from death certificates, although cause of death was not made available in our file to protect the participants' confidentiality. We used the time of survival from the second spirometric test to either death or the date last known to be alive as the time metric.

\section{Hospital admissions}

Hospital admission data were searched and events coded for any admissions that mentioned COPD in the time period following the second spirometric test. We used the time from the second spirometric to either the COPD hospital admission, death, or the date last known to be alive as the time metric.

\section{Analysis of data}

All analyses were conducted with SAS Version 8.2 (SAS Institute, Cary, NC, USA), SUDAAN Version 8.0 (RTI, Research Triangle Park, NC, USA), and SPSS Version 10 (SPSS Inc, Chicago, IL, USA). Logistic regression models were used to predict which participants were more likely to be missing spirometry measurements at the follow up visit (for example, did not survive to year 4 or could not perform the test) and to predict risk factors for subjects being in the group with the most rapidly declining lung function.

Our primary outcomes of interest in the survival models were death and COPD hospital admissions that occurred after the follow up evaluation, and the main predictor of interest in our analysis was lung function and the decline in lung function from the baseline visit to the follow up visit. Cox proportional hazard regression models were developed using the SUDAAN procedure SURVIVAL to account for differential follow up in cohort participants. Time of follow up was used as the underlying time metric. For deaths, the exit date (or censoring) was the date of death reported on the death certificate and, for survivors, the exit date was the date the participant was last known to be alive. Plots of the log-log survival curves for each covariate were produced to evaluate the proportional hazards assumptions. Age, sex, race, smoking status, education level, BMI, diabetes status, cardiovascular disease status, exercise level, and depression were included in the adjusted models.

\section{RESULTS}

The studied CHS cohort consisted of 5201 subjects;184 subjects with missing pulmonary function data and 94 who were missing data on covariates were excluded, leaving 4923 subjects available for analysis.

The demographic characteristics of the studied population are shown in table 1. Overall, 330 participants $(6.7 \%)$ had GOLD stage 3 or 4 COPD and $962(19.5 \%)$ had GOLD stage 2 COPD at baseline. Death before the follow up visit occurred in 447 participants, and an additional 1088 subjects either did not participate in the follow up visit or did not have pulmonary function testing done at that visit, leaving 3388 subjects with spirometric data available at the follow up visit. Significant predictors of not having follow up pulmonary function testing (because of death or unavailability) included older age, current smoking, lower educational level, depression, heart disease, lower exercise level, and lower level of lung function (table 1). 
Table 1 Demographic distribution of study participants, proportion with spirometric data at visit 6 (approximately 4 years after baseline visit), and the proportion of subjects in the most rapidly declining quartile of $F E V_{1}$ or $F E V_{1} / F V C$ ratio. From the Cardiovascular Health Study (CHS) 1989-90 and follow up through visit 6

\begin{tabular}{|c|c|c|c|c|c|c|}
\hline & \multicolumn{3}{|c|}{ Baseline ( $N=4923$ ) } & \multicolumn{3}{|c|}{ Follow up $(\mathrm{N}=3338)$} \\
\hline & $\mathrm{N}(\%)$ & $\begin{array}{l}\% \text { without } \\
\text { spirometry at } \\
\text { follow up }\end{array}$ & $\begin{array}{l}\text { Risk of no spirometry } \\
\text { at follow up } \\
\text { OR }(95 \% \mathrm{Cl})^{*}\end{array}$ & $\mathrm{~N}(\%)$ & $\begin{array}{l}\text { \% in most rapid } \\
\mathrm{FEV}_{1} \text { decline } \\
\text { quartile }\end{array}$ & $\begin{array}{l}\text { Risk of being in most } \\
\text { rapid } \mathrm{FEV}_{1} \text { decline } \\
\text { quartile } \\
\text { OR }(95 \% \mathrm{Cl})^{*}\end{array}$ \\
\hline \multicolumn{7}{|l|}{ Age group } \\
\hline $65-73$ & $1282(26.0)$ & 21.4 & 1.0 & 1007 (29.7) & 22.6 & 1.0 \\
\hline $74-77$ & 1470 (29.9) & 25.5 & $1.2(1.0$ to 1.5$)$ & 1095 (32.3) & 25.3 & $1.2(0.98$ to 1.5$)$ \\
\hline $78-81$ & 975 (19.8) & 31.4 & $1.6(1.3$ to 2.0$)$ & $669(19.8)$ & 25.1 & $1.2(0.9$ to 1.5$)$ \\
\hline $82-85$ & $695(14.1)$ & 40.3 & 2.1 (1.7 to 2.7$)$ & 415 (12.3) & 28.2 & 1.3 (1.01 to 1.7$)$ \\
\hline $86+$ & $501(10.2)$ & 59.7 & 4.9 (3.9 to 6.3$)$ & $202(6.0)$ & 24.8 & $1.2(0.8$ to 1.7$)$ \\
\hline \multicolumn{7}{|l|}{ Sex } \\
\hline Female & $2780(56.5)$ & 29.9 & $1.0(0.8$ to 1.1$)$ & 1949 (57.5) & 26.9 & $1.4(1.2$ to 1.6$)$ \\
\hline Male & $2143(43.5)$ & 32.8 & 1.0 & $1439(42.5)$ & 22.0 & 1.0 \\
\hline \multicolumn{7}{|l|}{ Race } \\
\hline White & 4695 (95.4) & 30.7 & 1.0 & 3254 (96.0) & 24.7 & 1.0 \\
\hline Black & $228(4.6)$ & 41.2 & $1.3(0.9$ to 1.7$)$ & $134(4.0)$ & 27.6 & $1.0(0.7$ to 1.5$)$ \\
\hline \multicolumn{7}{|l|}{ Smoking status } \\
\hline Current smoker & 571 (11.6) & 35.5 & $1.4(1.1$ to 1.7$)$ & $368(10.9)$ & 37.8 & $1.8(1.4$ to 2.3$)$ \\
\hline Former smoker & $2100(42.7)$ & 31.3 & $1.1(1.0$ to 1.3$)$ & $1442(42.6)$ & 23.2 & $1.1(0.9$ to 1.3$)$ \\
\hline Never smoker & 2252 (45.7) & 29.9 & 1.0 & $1578(46.6)$ & 23.2 & 1.0 \\
\hline \multicolumn{7}{|l|}{ BMI $\left(\mathrm{kg} / \mathrm{m}^{2}\right)$} \\
\hline$<20$ & $225(4.6)$ & 39.6 & $1.4(1.0$ to 1.9$)$ & $136(4.0)$ & 31.6 & $1.2(0.8$ to 1.7$)$ \\
\hline $21-24$ & 1765 (35.9) & 31.3 & 1.0 & $1213(35.8)$ & 26.1 & 1.0 \\
\hline $25-29$ & 2057 (41.8) & 29.6 & $0.9(0.8$ to 1.0$)$ & 1449 (42.8) & 23.3 & $0.9(0.8$ to 1.1$)$ \\
\hline$\geqslant 30$ & $876(17.8)$ & 32.6 & $1.0(0.8$ to 1.2$)$ & $590(17.4)$ & 24.1 & 0.9 (0.7 to 1.2$)$ \\
\hline \multicolumn{7}{|l|}{ Education level } \\
\hline$<12$ years & $1352(27.5)$ & 41.2 & 1.7 (1.4 to 2.0$)$ & $795(23.5)$ & 28.1 & $1.2(1.0$ to 1.5$)$ \\
\hline 12 years & $1397(28.4)$ & 30.4 & $1.4(1.2$ to 1.6$)$ & $972(28.7)$ & 24.4 & $1.0(0.9$ to 1.3$)$ \\
\hline$>12$ years & $2174(44.2)$ & 25.4 & 1.0 & $1621(47.8)$ & 23.4 & 1.0 \\
\hline \multicolumn{7}{|l|}{ Depressed } \\
\hline Yes & 1197 (24.3) & 39.8 & $1.4(1.2$ to 1.6$)$ & $720(21.2)$ & 26.4 & $1.0(0.8$ to 1.2$)$ \\
\hline No & $3726(75.7)$ & 28.4 & 1.0 & $2668(78.8)$ & 24.4 & 1.0 \\
\hline \multicolumn{7}{|l|}{ Diabetes } \\
\hline Yes & 1422 (28.9) & 37.7 & $1.4(1.2$ to 1.7$)$ & 2502 (73.9) & 23.1 & $0.9(0.7$ to 1.1$)$ \\
\hline No & 3501 (71.1) & 28.5 & 1.0 & $886(26.1)$ & 25.4 & 1.0 \\
\hline \multicolumn{7}{|c|}{ Cardiovascular disease } \\
\hline Yes & $1060(21.5)$ & 42.6 & $1.5(1.3$ to 1.8$)$ & $608(18.0)$ & 27.1 & $1.2(0.96$ to 1.4$)$ \\
\hline No & $3863(78.5)$ & 28.0 & 1.0 & $2780(82.0)$ & 24.3 & 1.0 \\
\hline \multicolumn{7}{|l|}{ Exercise level } \\
\hline Lowest & $482(9.8)$ & 50.8 & 2.1 (1.7 to 2.6$)$ & $237(7.0)$ & 29.5 & $1.3(0.9$ to 1.8$)$ \\
\hline 2 & $888(18.0)$ & 40.6 & $1.8(1.5$ to 2.1$)$ & $527(15.6)$ & 26.6 & $1.2(0.9$ to 1.5$)$ \\
\hline 3 & $1492(30.3)$ & 30.0 & $1.2(1.1$ to 1.4$)$ & $1045(30.8)$ & 27.1 & $1.2(1.03$ to 1.5$)$ \\
\hline Highest & 2061 (41.9) & 23.4 & 1.0 & 1579 (46.6) & 22.0 & 1.0 \\
\hline \multicolumn{7}{|l|}{ GOLD category† } \\
\hline GOLD 3 or 4 & $330(6.7)$ & 47.3 & 2.1 (1.6 to 2.8$)$ & $174(5.1)$ & 28.2 & $1.3(0.9$ to 1.9$)$ \\
\hline GOLD 2 & $962(19.5)$ & 35.8 & $1.3(1.1$ to 1.6$)$ & $618(18.2)$ & 31.7 & $1.6(1.2$ to 2.0$)$ \\
\hline GOLD 1 & $782(15.9)$ & 30.7 & $1.2(0.96$ to 1.5$)$ & $542(16.0)$ & 23.4 & $1.1(0.8$ to 1.4$)$ \\
\hline GOLD 0 & $981(19.9)$ & 30.0 & $1.6(1.2$ to 2.0$)$ & $687(20.3)$ & 23.8 & $1.2(0.9$ to 1.7$)$ \\
\hline Restricted & $510(10.4)$ & 39.4 & $1.2(0.9$ to 1.4$)$ & $309(9.1)$ & 25.9 & $1.1(0.8$ to 1.3$)$ \\
\hline Normal & $1358(27.6)$ & 22.1 & 1.0 & $1058(31.2)$ & 21.3 & 1.0 \\
\hline Total & 4923 & 31.2 & & 3388 & 24.8 & \\
\hline
\end{tabular}

$\mathrm{FEV}_{1}$, forced expiratory volume in 1 second; FVC, forced vital capacity; BMI, body mass index; OR, odds ratio; Cl, confidence interval.

*Adjusted for age, sex, race, smoking status, body mass index, education level, depression, diabetes, cardiovascular disease, exercise level, and GOLD category. tGOLD stage 3 or 4 ( $F E E_{1} / F V C<0.70$ and $F E V_{1}<50 \%$ predicted), GOLD stage 2 (FEV $1 / F V C<0.70$ and $\mathrm{FEV}_{1} \geqslant 50 \%$ to $<80 \%$ predicted), GOLD stage 1 ( $F E V_{1} / F V C<0.70$ and $\mathrm{FEV}_{1} \geqslant 80 \%$ ), restricted ( $F E V_{1} / F V C \geqslant 0.70$ and $F V C<80 \%$ predicted), GOLD stage 0 (presence of respiratory symptoms in the absence of any lung function abnormalityl, and no lung disease.

Table 2 Mean (SD) annual change in lung function parameter by quartiles of $F E V_{1}$ decline (as percentage of baseline value). From the Cardiovascular Health Study (CHS) 1989-90 and follow up through 1999

\begin{tabular}{llllll}
\hline $\begin{array}{l}\text { FEV } \\
\text { quartiles }\end{array}$ & $\mathbf{N}$ & $\begin{array}{l}\text { Mean (SD) } \\
\text { change in } \mathrm{FEV}_{\mathbf{1}}\end{array}$ & $\begin{array}{l}\text { Mean (SD) } \\
\text { change in FEV } \\
\text { (\% of baseline) }\end{array}$ & $\begin{array}{l}\text { Mean (SD) } \\
\text { change in FEV } \mathbf{1} \\
\text { (\% predicted) }\end{array}$ & $\begin{array}{l}\text { Mean (SD) change } \\
\text { in FEV } \mathbf{F} / \mathrm{FVC} \\
\text { (\% of baseline) }\end{array}$ \\
\hline 1 & 840 & $-110(52)$ & $-5.4(2.4)$ & $-4.6(2.2)$ & $-1.2(3.2)$ \\
2 & 854 & $-59(18)$ & $-2.7(0.4)$ & $-2.4(0.6)$ & $-0.7(1.9)$ \\
3 & 851 & $-28(13)$ & $-1.2(0.4)$ & $-1.1(0.5)$ & $-0.5(1.7)$ \\
4 & 843 & $41(121)$ & $3.6(11.8)$ & $1.7(5.2)$ & $1.4(7.5)$ \\
\hline
\end{tabular}

$\mathrm{FEV}_{1}$, forced expiratory volume in 1 second; FVC, forced vital capacity 
Table 3 Death rate, risk of death, hospitalisation rate for COPD, and risk of a COPD related hospital admission (from Cox proportional hazard models) stratified by baseline pulmonary function and rapid decline in the $\mathrm{FEV}_{1}$. From the Cardiovascular Health Study (CHS) 1989-90 and follow up through 1999

\begin{tabular}{|c|c|c|c|c|c|}
\hline & $\begin{array}{l}\text { Rapid decliners } \\
\text { (N) }\end{array}$ & $\begin{array}{l}\text { Death rate } \\
\text { (per } 1000 \\
\text { person-years) }\end{array}$ & $\begin{array}{l}\text { Risk of death } \\
\text { Adjusted }{ }^{*} \text { HR }(95 \% \text { Cl) }\end{array}$ & $\begin{array}{l}\text { COPD related hospital } \\
\text { admissions during } \\
\text { follow up (per } 1000 \\
\text { person-years) }\end{array}$ & $\begin{array}{l}\text { Risk of COPD related } \\
\text { hospital admissions } \\
\text { Adjusted }{ }^{*} \mathrm{HR}(95 \% \mathrm{Cl})\end{array}$ \\
\hline \multirow[t]{2}{*}{ GOLD 3 or $4 \dagger$} & Yes (49) & 118 & $2.0(1.2$ to 3.4$)$ & 170 & 2.0 (1.2 to 3.3$)$ \\
\hline & No (125) & 60 & 1.0 & 89 & 1.0 \\
\hline \multirow[t]{2}{*}{ GOLD 2} & Yes (196) & 58 & $1.1(0.8$ to 1.5$)$ & 70 & $1.3(0.9$ to 1.9$)$ \\
\hline & No (422) & 54 & 1.0 & 48 & 1.0 \\
\hline \multirow[t]{2}{*}{ GOLD 1} & Yes (127) & 39 & $1.4(0.9$ to 2.2$)$ & 29 & 1.5 (0.7 to 3.2$)$ \\
\hline & No (415) & 31 & 1.0 & 21 & 1.0 \\
\hline \multirow[t]{2}{*}{ Restricted } & Yes (80) & 69 & $1.2(0.7$ to 2.0$)$ & 38 & $2.1(0.6$ to 7.2$)$ \\
\hline & No (229) & 54 & 1.0 & 20 & 1.0 \\
\hline \multirow[t]{2}{*}{ GOLD 0} & Yes (163) & 44 & $1.9(1.2$ to 2.9$)$ & 20 & $1.3(0.6$ to 2.8$)$ \\
\hline & No (524) & 22 & 1.0 & 14 & 1.0 \\
\hline \multirow[t]{2}{*}{ Normal } & Yes (225) & 31 & $1.6(1.1$ to 2.4$)$ & 13 & $1.4(0.6$ to 3.3$)$ \\
\hline & No (833) & 19 & 1.0 & 7 & 1.0 \\
\hline \multirow[t]{2}{*}{ All } & Yes (840) & 49 & 1.5 (1.2 to 1.7$)$ & 40 & $1.6(1.3$ to 2.0$)$ \\
\hline & No (2548) & 32 & 1.0 & 22 & 1.0 \\
\hline
\end{tabular}

$\mathrm{FEV}_{1}$, forced expiratory volume in 1 second; $\mathrm{FVC}$, forced vital capacity; OR, odds ratio; $\mathrm{Cl}$, confidence interval.

*Adjusted for age, sex, race, smoking status, body mass index, education level, depression, diabetes, cardiovascular disease, exercise level, and GOLD category. †GOLD stage 3 or 4 ( $F E V_{1} / F V C<0.70$ and $\mathrm{FEV}_{1}<50 \%$ predicted), GOLD stage 2 (FEV $1 / \mathrm{FVC}<0.70$ and $\mathrm{FEV}_{1} \geqslant 50 \%$ to $<80 \%$ predicted), GOLD stage 1 ( $F E V_{1} / F V C<0.70$ and $\mathrm{FEV}_{1} \geqslant 80 \%$ ), restricted ( $F \mathrm{FV}_{1} / \mathrm{FVC} \geqslant 0.70$ and $\mathrm{FVC}<80 \%$ predicted), GOLD stage 0 (presence of respiratory symptoms in the absence of any lung function abnormalityl, and no lung disease.

Subjects in the most rapidly declining quartile of $\mathrm{FEV}_{1}$ had a mean annual loss of $110 \mathrm{ml}$, which was $5.4 \%$ of the baseline level (table 2). All of the subjects in this group lost at least $3.5 \%$ of their baseline $\mathrm{FEV}_{1}$ annually. The 840 subjects in the more rapidly declining quartile were more likely to have respiratory symptoms at baseline $(53 \% v 45 \%)$, to be current smokers $(17 \% \vee 9 \%)$, and to be female $(62 \% \vee 56 \%)$ than the 2548 subjects in the other three quartiles $(\mathrm{p}<0.05$ for each comparison).

Death during follow up occurred in 712 of the 3388 subjects $(21.0 \%)$ who had repeat lung function testing. The follow up period after the repeat lung function test was a median of 6.5 years and a maximum of 7.0 years for the cohort. Of the 1088 subjects not available for pulmonary function testing at the second visit, 443 (40.7\%) died during the follow up period. Death rates, stratified by baseline lung function and rapid $\mathrm{FEV}_{1}$ decline, ranged from 19/1000 person-years among normal subjects without rapid lung

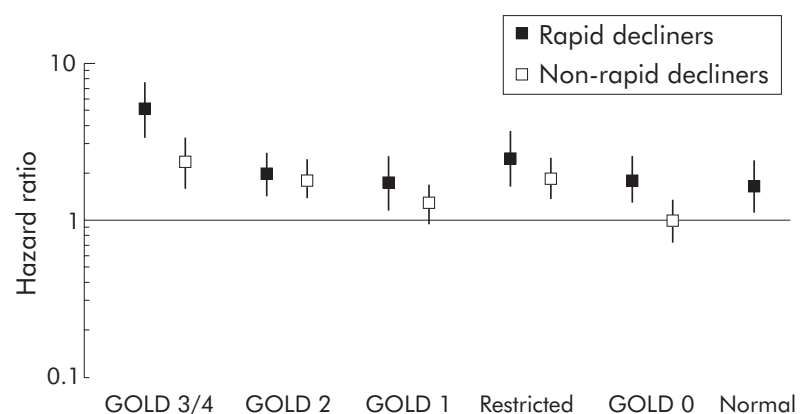

Figure 1 Results from Cox proportional hazard models predicting death. Normal subjects without rapid decline are the reference group, and the models are adjusted for age, sex, race, smoking status, body mass index, education level, depression, cardiovascular disease, and exercise level. From the Cardiovascular Health Study (CHS) 1989-90 and follow up through 1999. Global Initiative on Obstructive Lung Disease (GOLD) stage 3 or 4 (FEV $1 / F V C<0.70$ and $\mathrm{FEV}_{1}<50 \%$ predicted), GOLD stage 2 ( $\mathrm{FEV}_{1} / \mathrm{FVC}<0.70$ and $\mathrm{FEV}_{1} \geqslant 50 \%$ to $<80 \%$ predicted), GOLD stage 1 (FEV $1 / F V C<0.70$ and $\left.\mathrm{FEV}_{1} \geqslant 80 \%\right)$, restricted ( $F E V_{1} / F V C \geqslant 0.70$ and $F V C<80 \%$ predicted), GOLD stage 0 (presence of respiratory symptoms in the absence of any lung function abnormalityl, and no lung disease. function decline to $118 / 1000$ person-years among subjects with GOLD 3 or 4 COPD and a rapid decline in lung function (table 3). Overall, subjects with a more rapid decline in $\mathrm{FEV}_{1}$ were at higher risk of death (hazard ratio (HR) 1.5, 95\% CI 1.2 to 1.7), with HRs ranging from 1.1 to 2.0 in the stratified analyses (table 3 ). Across the entire cohort, the interaction term between the initial GOLD stage and rapid decline in lung function for the outcome of death was not significant $(p=0.16)$. The interaction between GOLD stage, lung function decline, and death is shown in fig 1.

Among the 3388 participants with repeat lung function testing at year $4,521(15.4 \%)$ had had at least one COPD related hospital admission during the follow up period. Hospital admission rates, stratified by baseline lung function and rapid $\mathrm{FEV}_{1}$ decline, ranged from 7/1000 person-years among normal participants without rapid lung function decline to 170/1000 person-years among those with GOLD 3 or 4 COPD and a rapid decline in lung function (table 3 ). Overall, participants with a more rapid decline in $\mathrm{FEV}_{1}$ had

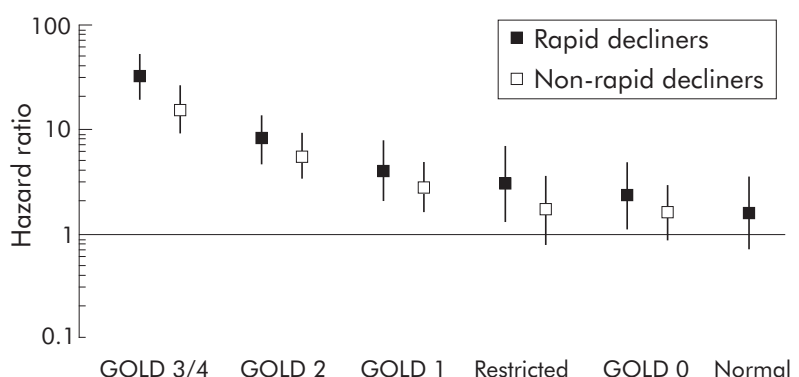

Figure 2 Results from Cox proportional hazard models predicting the first COPD related hospital admission. Normal subjects without a rapid decline in lung function are the reference group, and the models are adjusted for age, sex, race, smoking status, body mass index, education level, depression, cardiovascular disease, and exercise level. From the Cardiovascular Health Study (CHS) 1989-90 and follow up through 1999. Global Initiative on Obstructive Lung Disease (GOLD) stage 3 or 4 (FEV $1 / F V C<0.70$ and $\mathrm{FEV}_{1}<50 \%$ predicted), GOLD stage 2 ( $\mathrm{FEV}_{1} /$ FVC $<0.70$ and $\mathrm{FEV}_{1} \geqslant 50 \%$ to $<80 \%$ predicted), GOLD stage 1 (FEV 1 / $\mathrm{FVC}<0.70$ and $\left.\mathrm{FEV}_{1} \geqslant 80 \%\right)$, restricted $\left(\mathrm{FEV}_{1} / \mathrm{FVC} \geqslant 0.70\right.$ and $\mathrm{FVC}$ $<80 \%$ predicted), GOLD stage 0 (presence of respiratory symptoms in the absence of any lung function abnormality), and no lung disease. 
an increased risk of COPD related hospital admissions (HR 1.6 , 95\% CI 1.3 to 2.0 ), ranging from $30 \%$ to a twofold increase in the stratified analyses (table 4). Across the entire cohort, the interaction term between the initial GOLD stage and rapid decline in lung function for the outcome of COPD related hospital admission was not significant $(p=0.86)$. The interaction between GOLD stage, lung function decline, and COPD related hospital admissions is shown in fig 2 .

\section{DISCUSSION}

In this large cohort of an elderly population we found that subjects who lost lung function more rapidly between the baseline and follow up visit 4 years later were at an increased risk for death and COPD related hospital admissions during the follow up period. While these effects were modest, with HRs of 1.5 (95\% CI 1.2 to 1.7) for death and 1.6 (95\% CI 1.3 to 2.0) for COPD related hospital admissions, they still correspond to a $50-60 \%$ increase in risk. These results are similar to those seen in another US cohort that is much younger than the one studied here. ${ }^{24}$ This analysis also highlights some of the challenges in any work that looks at the decline in lung function in a population, including survivor bias and choosing the best way to classify rapid lung function decline.

As would be expected, we found a strong and consistent relation between the baseline lung function and risk of death or COPD related hospital admissions, even when the cohort was limited to people surviving to the follow up visit without a rapid lung function decline. This relation is shown in table 3 where the risk of death was three times higher $(60 v 19$ per 1000 person-years) when subjects with GOLD 3 or 4 COPD at baseline were compared with normal subjects. An even stronger effect was noted for COPD related hospital admissions where the corresponding values were $89 v 7$ admissions per 1000 person-years.

The measurement of lung function decline fundamentally depends upon survival up to the time of the repeat measurement. In addition, participants must be healthy enough to perform spirometric tests. In our analysis many factors that were significant predictors of death (such as older age, co-morbid disease, current smoking) also predicted the absence of follow up spirometric data (table 2). In addition, of the participants known to be alive at the follow up visit, the risk of death during follow up among those who did not have spirometric data was twice that of those who did $(40.7 \% \vee 21.0 \%)$. Thus, in this analysis of the CHS, people who had follow up spirometric data probably represented a healthier survivor cohort that cannot be generalised to the sicker participants who died in the first 4 years or were unable to contribute the second spirometric measurement. This finding is consistent with those from other studies that suggest that lung function decline in cohorts (where one would see a survivor effect) is less than that estimated in cross sectional studies, ${ }^{25}$ or that people unable to complete a clinical trial have a more rapid deterioration in their health status and lung function. ${ }^{26}$ It may also be possible, however, that some participants attended the follow up visit because they thought they were sick, potentially biasing these findings towards a population that is more sick.

In a previous analysis of data from this cohort Griffith et $a^{27}$ showed that baseline factors of history of dyspnoea, presence of emphysema, and use of beta-blocker medications actually predicted a smaller decline in $\mathrm{FEV}_{1}$ and FVC, although each of these factors was also associated with significantly lower lung function levels at the baseline examination. This combination of findings suggests a survivor effect where, for example, people with emphysema at baseline who survived to the follow up examination were probably healthier than those who died or were unable to participate in the follow up examination.

Among the survivors who had follow up lung function data at year 4, we classified a group of rapid decliners based on the annual percentage decrease from the baseline $\mathrm{FEV}_{1}$. There are potential disadvantages to this approach in that subjects with lower baseline lung function are more likely to have larger changes in their follow up values (either increases or decreases). ${ }^{28}$ Alternative approaches such as looking at changes in the absolute $\mathrm{FEV}_{1}$ value or the percentage change in $\mathrm{FEV}_{1}$ as a proportion of the predicted $\mathrm{FEV}_{1}$ value can bias against subjects with lower initial $\mathrm{FEV}_{1}$ values where small changes can still have large clinical relevance..$^{29} 30$

Our group of rapid decliners who had a mean loss of $110 \mathrm{ml} \mathrm{FEV}$ annually (at least $3.5 \%$ of their baseline $\mathrm{FEV}_{1}$ value annually) can be compared with "rapid decliners" in other cohorts. In one study of workers exposed to grain dust, a rapid decline in lung function was defined at $\geqslant 90 \mathrm{ml}$ per year, ${ }^{31}$ and in 4451 participants in the Honolulu Heart Program rapid decliners had a decrease of $\geqslant 60 \mathrm{ml}$ per year. ${ }^{32}$

People can lose $\mathrm{FEV}_{1}$ for several reasons, including worsening obstruction and the loss of FVC which, in turn, can be due to the development of restrictive disease, congestive heart failure, obesity, or other factors. Age itself is a significant predictor of lung function decline with larger decrements of $\mathrm{FEV}_{1}$ associated with greater age. ${ }^{33}$ Our results suggest that, even in an elderly population, lung function measurements provide prognostic information. If lung function is declining rapidly, factors that may be causing this should be evaluated.

An interesting finding of our study was that the risk associated with being a "rapid decliner" for outcomes such as COPD related hospital admissions and deaths may vary by baseline lung function status. For example, among subjects initially classified as GOLD 0, rapid decliners had a higher risk of death (HR 1.9, 95\% CI 1.2 to 2.9 ) whereas, among subjects initially classified as GOLD 2, this was not found (HR $1.1,95 \%$ CI 0.8 to 1.5 ). Although this may have been related to our definition of "rapid decliners", it may also suggest that the loss of lung function is one of several important factors in the prognosis of COPD patients. The bias introduced by loss of the sickest participants who did not survive or were unable to perform follow up lung function tests is an alternative explanation for the variation in risk associated with rapid $\mathrm{FEV}_{1}$ decline by baseline stage of lung function. Annual measurements of lung function would have provided a much fuller picture of the role of baseline stage and modification of risk of rapid decline of $\mathrm{FEV}_{1}$ on major morbidity and mortality.

This analysis has certain limitations. We only had two measurements of lung function available to calculate lung function decline. Thus, a person who had a particularly good or bad day at either assessment could have been misclassified. Our primary way of dealing with this problem was to use only two categories of lung function decline rather than a continuous measure. Smoking status, which is an important predictor of mortality, was not independently validated with biomarkers, so some misclassification probably occurred. It is unclear what direction the bias from this misclassification would take but, due to social desirability, some current smokers may have responded as "former smokers" which would bias the results towards the null. Respiratory symptoms were all self-reported and not independently validated. The strict classification using GOLD criteria requires the use of a post-bronchodilator $\mathrm{FEV}_{1}$ which was not available in this study. ${ }^{3}$ We did not have data available on total lung capacity which is needed for the strict definition of restrictive lung disease, ${ }^{34}$ so it is possible that some of those 
classified as restrictive may have had other pathology or normal lung volumes. ${ }^{35}$

In conclusion, in this elderly cohort both the modified GOLD COPD stage and a rapid decline in lung function predicted death and COPD related admissions to hospital in a follow up period of up to 7 years. These data suggest that the GOLD classification stages may have useful prognostic value even in an elderly population, particularly when combined with measures of lung function decline.

\section{ACKNOWLEDGEMENTS}

The authors thank the staff and participants in the Cardiovascular Health Study (CHS) for their important contributions. The CHS is conducted and supported by the National Heart Lung and Blood Institute (NHLBI) in collaboration with the CHS Investigators. This manuscript was not prepared in collaboration with investigators of the CHS and does not necessarily reflect the opinions or views of the CHS or the NHLBI. The authors also thank Dana Hazen, Kara Guiliani, and Rebecca Copeland for their valuable contributions to this work.

\section{Authors' affiliations}

D M Mannino, Division of Pulmonary and Critical Care Medicine, University of Kentucky Medical Center, Lexington, KY, USA

K J Davis, GlaxoSmithKline Research and Development, Research Triangle Park, NC, USA

Funded by a research grant from GlaxoSmithKline.

Competing interests: DM serves on advisory boards for Boehringer Ingelheim, GlaxoSmithKline and Ortho Biotech, is on the speakers' bureau for Boehringer Ingelheim, Pfizer, and Dey, and has received research grants from GlaxoSmithKline and Pfizer. KD is a current employee of GlaxoSmithKline Research and Development and owns GlaxoSmithKline stock options.

\section{REFERENCES}

1 Chen JC, Mannino DM. Worldwide epidemiology of chronic obstructive pulmonary disease. Curr Opin Pulm Med 1999;5:93-9.

2 Mannino DM, Homa DM, Akinbami $\sqcup$, et al. Chronic obstructive pulmonary disease surveillance-United States, 1971-2000. MMWR Surveill Summ 2002;51:1-16.

3 Pauwels RA, Buist AS, Calverley PM, et al. Global Strategy for the Diagnosis, Management, and Prevention of Chronic Obstructive Pulmonary Disease. NHLBI/WHO Global Initiative for Chronic Obstructive Lung Disease (GOLD) workshop summary. Am J Respir Crit Care Med 2001;163:1256-76.

4 Snider GL. Nosology for our day: its application to chronic obstructive pulmonary disease. Am J Respir Crit Care Med 2003;167:678-83.

5 Mannino DM, Buist AS, Petty TL, et al. Lung function and mortality in the United States: data from the First National Health and Nutrition Examination Survey follow up study. Thorax 2003;58:388-93.

6 Mannino DM, Aguayo SM, Petty TL, et al. Low lung function and incident lung cancer in the United States: data From the First National Health and Nutrition Examination Survey follow-up. Arch Intern Med 2003;163:1475-80.

7 Mannino DM, Ford ES, Redd SC. Obstructive and restrictive lung disease and markers of inflammation: data from the Third National Health and Nutrition Examination. Am J Med 2003;114:758-62.

8 Celli BR, Cote CG, Marin JM, et al. The body-mass index, airflow obstruction, dyspnea, and exercise capacity index in chronic obstructive pulmonary disease. N Engl J Med 2004;350:1005-12.
9 Donaldson GC, Seemungal TA, Patel IS, et al. Longitudinal changes in the nature, severity and frequency of COPD exacerbations. Eur Respir $J$ 2003;22:931-6.

10 Anthonisen NR. Prognosis in chronic obstructive pulmonary disease: results from multicenter clinical trials. Am Rev Respir Dis 1989:140:S95-9.

11 Hospers JJ, Postma DS, Rijcken B, et al. Histamine airway hyperresponsiveness and mortality from chronic obstructive pulmonary disease: a cohort study. Lancet 2000;356:1313-7.

12 Hole DJ, Watt GC, Davey-Smith G, et al. Impaired lung function and mortality risk in men and women: findings from the Renfrew and Paisley prospective population study. BMJ 1996;313:711-5.

13 Knuiman MW, James AL, Divitini ML, et al. Lung function, respiratory symptoms, and mortality: results from the Busselton Health Study. Ann Epidemiol 1999:9:297-306.

14 Schunemann HJ, Dorn J, Grant BJ, et al. Pulmonary function is a long-term predictor of mortality in the general population: 29-year follow-up of the Buffalo Health Study. Chest 2000;118:656-64.

15 Anthonisen NR, Wright EC, Hodgkin JE. Prognosis in chronic obstructive pulmonary disease. Am Rev Respir Dis 1986;133:14-20.

16 Burrows B. Predictors of loss of lung function and mortality in obstructive lung diseases. Eur Respir Rev 1991;1:340-5.

17 Fletcher C, Peto R, Tinker CM, et al. The natural history of chronic bronchitis and emphysema. Oxford: Oxford University Press, 1976.

18 Mannino DM, Holguin F, Pavlin BI, et al. Risk factors for prevalence of and mortality related to restriction on spirometry: findings from the First National Health and Nutrition Examination Survey and follow-up. Int J Tuberc Lung Dis 2005;9:613-21.

19 Fried LP, Borhani NO, Enright P, et al. The Cardiovascular Health Study: design and rationale. Ann Epidemiol 1991;1:263-76.

20 American Thoracic Society. Standardization of spirometry. Am Rev Respir Dis 1979;119:831-8

21 Knudson RJ, Slatin RC, Lebowitz MD, et al. The maximal expiratory flowvolume curve. Normal standards, variability, and effects of age. Am Rev Respir Dis 1976;113:587-600.

22 Anon. Executive summary of the clinical guidelines on the identification, evaluation, and treatment of overweight and obesity in adults. Arch Intern Med 1998;158:1855-67.

23 Steffens DC, Helms MJ, Krishnan KR, et al. Cerebrovascular disease and depression symptoms in the cardiovascular health study. Stroke 1999;30:2159-66

24 Mannino DM, Reichert MM, Davis KJ. Lung function decline and outcomes in an adult population. Am J Respir Crit Care Med 2006 (in press).

25 van Pelt W, Borsboom GJ, Rijcken B, et al. Discrepancies between longitudinal and cross-sectional change in ventilatory function in 12 years of follow-up. Am J Respir Crit Care Med 1994;149:1218-26.

26 Calverley PM, Spencer S, Willits L, et al. Withdrawal from treatment as an outcome in the ISOLDE study of COPD. Chest 2003;124:1350-6.

27 Griffith KA, Sherrill DL, Siegel EM, et al. Predictors of loss of lung function in the elderly: the Cardiovascular Health Study. Am J Respir Crit Care Med $2001 ; 163: 61-8$.

28 Burrows B, Knudson RJ, Camilli AE, et al. The "horse-racing effect" and predicting decline in forced expiratory volume in one second from screening spirometry. Am Rev Respir Dis 1987;135:788-93.

29 Lange $\mathbf{P}$, Nyboe J, Appleyard $M$, et al. Ventilatory function and chronic mucus hypersecretion as predictors of death from lung cancer. Am Rev Respir Dis 1990;141:613-7.

30 Sherman CB, Xu X, Speizer FE, et al. Longitudinal lung function decline in subjects with respiratory symptoms. Am Rev Respir Dis 1992;146:855-9.

31 Post W, Heederik D, Houba R. Decline in lung function related to exposure and selection processes among workers in the grain processing and animal feed industry. Occup Environ Med 1998;55:349-55.

32 Burchfiel CM, Marcus EB, Sharp DS, et al. Characteristics associated with rapid decline in forced expiratory volume. Ann Epidemiol 1996;6:217-27.

33 Ware JH, Dockery DW, Lovis TA, et al. Longitudinal and cross-sectional estimates of pulmonary function decline in never-smoking adults. Am J Epidemiol 1990;132:685-700.

34 American Thoracic Society. Lung function testing: selection of reference values and interpretive strategies. Am Rev Respir Dis 1991;144:1202-18.

35 Aaron SD, Dales RE, Cardinal P. How accurate is spirometry at predicting restrictive pulmonary impairment? Chest 1999;115:869-73. 